\title{
Research on Demand Forecast of Passenger Transfer of Rail Transit and Intercity Railway-Taking Beijing as an Example
}

\author{
Cong Zhou, a \\ ${ }^{1}$ Transport College, Beijing Transportation University, Beijing, 100044, China \\ aemail 798421346@qq.com
}

\begin{abstract}
Keywords: Demand forecast, Passenger transfer, Rail transit, Intercity railway
\end{abstract}
\begin{abstract}
With the increasing population of cities and the increasingly powerful urban functions, the carriers of urban transportation and intercity traffic have been put to severe test. Beijing is an international metropolis, and its rail transit and intercity rail demand forecast are of great significance. In this paper, the four-stage model is used to investigate the related data, and the forecast of rail transit and intercity rail demand in Beijing is given.
\end{abstract}

\section{Introduction}

With the expansion of the scale of the city rail transit network, rail lines and station traffic gradually increased, the main passenger pressure transfer station, if you encounter unexpected events will also cause great security risks, seriously affect the safety of the passengers. How to carry out the station passenger transport organization operation is an important challenge facing the previous work station passenger station attendant are relying on experience or the emergency plan has been fixed to handle, the passenger organization operation largely depends on the degree of experience in road station attendant. At present, both domestic and international researches on passenger transport of rail transit transfer station are based on the operation management under static passenger flow, and lack of flexibility. With the acceleration of the urbanization process in China, the pressure of urban traffic is becoming more and more obvious with the increase of urban population. In order to solve the urban traffic pressure, the large and medium-sized cities in China have greatly developed rail transit construction, and gradually formed a network layout. However, between the rail transfer vital rail transfer form choice should be based on line network planning and passenger flow forecasting, follow the principle of people-oriented, in the premise of transfer to fully meet demand, to achieve economic and rational design of the station. Therefore, it is very important to carry on the theoretical research of passenger train organization optimization. The passenger flow and passenger flow of transfer station are different in different dates and time periods, and the passenger train organization is different from each other. The set plan in passenger station operation or only by experience is not enough, on the passenger flow station and passenger flow forecast with specific analysis of passenger transport management can contribute to the subway station, can provide data support for the auxiliary passenger station staff. In a word, it is necessary to adopt the corresponding passenger transport organization plan according to the passenger flow forecast data at different time periods, and it is of great significance to predict passenger flow and passenger transport organization.

\section{Demand Forecast Method of Passenger Transfer- Four-stage Models}

Research and application of four stage model development, the emergence of many of its improvement and adapt to a special case of the model, but the fact the model prediction based on the basic principle and characteristics of city residents travel is still the same, the logic model analysis and solving the same.

The first stage is to generate forecasts. According to the characteristics of the study area, we can predict the traffic generation of a city in the future. Because of the complexity of traffic generation, the main useful nature, employment, car ownership, family size and personnel composition, there are both quantitative and non-quantitative factors. The common models of traffic generation forecasting 
include generation rate model, class generation rate model, time series model and regression analysis model.

The second stage is distribution forecast. The distribution prediction is to change the travel volume of each cell obtained by the prediction of the occurrence and attraction of traffic into the spatial OD quantity between the traffic cells, that is, the OD matrix. The current methods of traffic distribution forecasting are generally divided into two categories, one is the growth coefficient method, and the other is the comprehensive method.

Third stage is the mode forecast. The mode prediction is to divide the proportion of traveler's trip and choice of vehicles, and predict the traffic share of various traffic modes. The residents travel survey data based on when people travel traffic mode choice behavior model to predict changes in infrastructure or service conditions, the change of traffic between the traffic demand. The modeling method generally has two kinds: one is under the assumptions that the future will continue to continue the historical changes, changes of different traffic modes; the two is from the angle of the city planning, how to through the expansion of various traffic facilities to guide people to travel, and how to formulate various traffic management rules to achieve the desired traffic division.

The fourth stage is the traffic mode forecast. Traffic assignment is OD traffic will be predicted, according to certain rules in accordance with the actual allocation to specific transportation network, and then calculate the road network traffic flow, the expenses of the OD matrix, and the city traffic network usage to make analysis and evaluation.

\section{Demand Forecast of Passenger Transfer of Beijing Rail Transit}

The OD matrix of trip can be obtained from trip generation and distribution. In order to predict the passenger flow of rail transit, OD transformation of each traffic mode must be carried out, and the OD matrix of rail transit mode is separated. Establish the various modes of transportation road network, get the various forms of the generalized cost shortest path matrix, and considering the transfer time, walking time and ends of public transport fares, unified conversion value after using the modified Logit model to describe the mode of people's choice. The rail transportation and public transportation OD matrix, the basic principle of user equilibrium model of passenger flow distribution in the integrated network rail transportation based on general in rail transit passenger flow distribution, the analysis object includes all ground bus and rail transit network of the comprehensive, user equilibrium model with nonlinear mathematical programming model. The objective function is the minimization of user cost, and the constraint is the mutual balance of OD flow. The model parameters are shown in the following table:

Table 1. Basic Parameters of Beijing Rail Transit Model

\begin{tabular}{|c|c|c|}
\hline Item & Category & Parameter value \\
\hline \multirow{2}{*}{ Mean departure interval (min) } & Bus & 10 \\
\cline { 2 - 3 } & Tube & 4 \\
\hline \multirow{2}{*}{ Mean Stopping time (min) } & Bus & 1 \\
\cline { 2 - 3 } Mean fee of unit distance (Yuan/km) & Tube & 2 \\
\cline { 2 - 3 } & Bus & 0.3 \\
\hline \multirow{2}{*}{ Mean transfer time } & Tube & 0.5 \\
\cline { 2 - 3 } & Bus transfer & 7 \\
\cline { 2 - 3 } & Tube transfer & 5 \\
\hline
\end{tabular}

The passenger flow distribution in comprehensive public transport network, the flow distribution map using analysis software can get certain integrated network, can intuitively understand the distribution of passenger flow in rail network, bus network and pedestrian network; public traffic 
each site by lowering the volume and cross flow, can know each bus station by lowering the volume and flow of each section is clear; the figure and table the inter site transfer times, generalized cost, distance and time in the car. Based on the analysis of the passenger flow distribution statistics, can get the rail transit transfer station in and out of traffic, the transfer volume in all directions, on the line between. The station passenger flow attraction area method is based on the traffic generation, the four phase distribution for the amount of trip distribution between different traffic zones on the traffic zone division of travel mode, statistics of the city rail transit line station passenger flow attraction area, according to the passenger flow attraction area occupied in the traffic area in the area the amount of traffic generated, according to the probability model of the trip mode chain generating traffic assigned to each station, the city rail transit station passenger volume. According to the characteristics of different types of passenger service station, the station to determine the peak hour factor is different, resulting in the rail transit station peak hour traffic; the search process in the calculation area attract passenger station, by marking the travel path of each of the OD, and then can get out of the station the station through the statistical total amount for the transfer; in addition to its own station, as the intermediate station near the passenger to attract, but also bear the transit passenger line. The calculation of the entrance, exit and transfer volume of transfer station is quite complicated, and it can also be counted through the path of search process. According to the route choice between different OD trips, the passenger volume of the transfer station is calculated and the transfer volume is 512638 passengers per day.

\section{Demand Forecast of Passenger Transfer of Beijing Intercity Railway}

Beijing intercity railway has won the intercity passenger transportation market with its advanced and reliable technical equipment, humanized service system, efficient and convenient transportation products and public transport organization mode. The passenger ticket information and historical survey data based on the Beijing South Railway Station, carries on the system analysis of Beijing intercity passenger, in order to provide the basis for further optimization of passenger organization of Beijing high speed railway and bus scheme. Analysis of factors influencing factors on passenger traffic changes involved a lot, a region of the degree of social and economic development, the characteristics of political culture, geographical conditions, the distance between the city zone, the main industry product structure and so on will affect the residents travel consciousness and behavior, to form a unique passenger flow law. From the point of view of passengers, the main influencing factors are personal attributes and social attributes. Among them, personal attributes include age, gender, social attributes, including occupation, travel purpose, income, travel sources, trips and so on. The model parameters are shown in the following table:

Table 2. Basic Parameters of Beijing Intercity Railway Model

\begin{tabular}{|c|c|c|}
\hline Item & Category & Parameter value \\
\hline \multirow{2}{*}{ Mean departure interval (min) } & Intercity bus & 60 \\
\cline { 2 - 3 } & Intercity railway & 40 \\
\hline \multirow{2}{*}{ Mean Stopping time (min) } & Intercity bus & 5 \\
\cline { 2 - 3 } Mean fee of unit distance (Yuan/km) & Intercity railway & 3 \\
\cline { 2 - 3 } & Intercity bus & 0.6 \\
\hline \multirow{2}{*}{ Mean transfer time } & Intercity railway & 0.8 \\
\cline { 2 - 3 } & Intercity bus transfer & 20 \\
\cline { 2 - 3 } & Intercity railway transfer & 10 \\
\cline { 2 - 3 } & Intercity bus-Intercity railway & 40 \\
\hline
\end{tabular}

Beijing traffic on Friday to Monday between the larger, which on Friday was the largest, that many passengers travel since Friday after ran on Saturday and Sunday, has the basic characteristics of 
reentry, similar to the commuter flow: weekend trips flow is relatively large and relatively small daily Monday. Beijing intercity high-speed railway for private passenger travel proportion is slightly higher than the proportion of business travel; business travel passenger is the biggest business flow; because private travel is the largest proportion in the visiting flow characteristic and other line does not reflect the significant difference compared. To a certain extent, Beijing high speed still has great potential in the commuter flow based on the city effect and the tourist flow based on passenger flow induced effect. Passengers on the Beijing Intercity High-Speed Railway are employees of the company or institutions, and this ratio is higher than that of other lines. This shows that Beijing high-speed passenger level and income level is relatively high, can be for its high quality of service requirements, with higher consumption capacity and other characteristics of the implementation of the corresponding marketing measures. Beijing Intercity High-Speed Railway Passenger speed approval rank is speed, convenience, comfort, safety, punctuality and fares, among which the lowest degree of acceptance of fares. From the income structure, Beijing between the low level of income ratio is significantly lower than the other passenger line to further improve the conditions in capacity, can be taken as additional part of the discount card or discount ticket form, increase the incomes of the poor appeal to expand a pedestrian group base. The transfer volume of Beijing intercity railway is 125561 passengers per day.

\section{Conclusion}

Transfer is an important phenomenon in rail transit and intercity railway. By using the four-stage model, combined with the parameters of the rail transit model and intercity railway model, we calculate the demand forecasting of Beijing rail transit and intercity rail to provide a new way for the establishment of transportation hub management strategy of Beijing.

\section{Acknowledgements}

This research is the result of the "Innovation Training Project of University Students of Beijing Transportation University".

\section{References}

[1] Deng Ji, Zhao Liang, Zheng Xiaowei, Application of Analysis on Passenger Flow Characteristics in the Period of Feasibility Study for Urban Rail Transit Projects [J]. Urban Rapid Rail Transit, 2016, 29(1): 87-91+113.

[2] Wang Weiwei, Study on Forecast of Railway Passenger Flow Volume under Influence of High-speed Railways [J]. Railway Transport and Economy, 2016, 38(4): 42-46+51.

[3] Zhang Xinming, Study on Forecasting of Passenger Flow Sharing Ratio in Traffic Hub based on Markov Model [J]. Transportation Science \& Technology, 2016(3): 180-182.

[4] Leng Biao, Zeng Jiabei, Research on Forecast Model of Passenger Flow in Beijing Metro Transfer Station [J]. Railway Transport and Economy, 2012, 34(5): 71-75. 